\title{
Association Between a Serotonin Transporter Gene Variant and Hopelessness Among Men in the Heart and Soul Study
}

\author{
Kirsten Neudoerffer Kangelaris, MD ${ }^{1,2,6}$, Eric Vittinghoff, $P h D^{3}$, Christian Otte, $M D^{5}$, \\ Beeya $\mathrm{Na}, \mathrm{MPH}^{3}$, Andrew D. Auerbach, $\mathrm{MD}^{2}$, and Mary A. Whooley, MD ${ }^{1,4}$
}

'Department of Medicine, Division of General Internal Medicine, University of California, San Francisco, San Francisco, CA, USA; ${ }^{2}$ Division of Hospital Medicine, University of California, San Francisco, San Francisco, CA, USA; ${ }^{3}$ Department of Epidemiology and Biostatistics, University of California, San Francisco, San Francisco, CA, USA; ${ }^{4}$ Division of General Internal Medicine, Veterans Affairs Medical Center, San Francisco, San Francisco, CA, USA; ${ }^{5}$ Department of Psychiatry and Psychotherapy, University Medical Center Hamburg-Eppendorf, Hamburg, Germany;

${ }^{6}$ Parnassus Ave UC Hall, University of California, San Francisco, San Francisco, CA, USA.

BACKGROUND: Hopelessness is associated with mortality in patients with cardiac disease even after accounting for severity of depression. We sought to determine whether a polymorphism in the promoter region of the serotonin transporter gene (5-HTTLPR) is associated with increased hopelessness, and whether this effect is modified by sex, age, antidepressant use or depression in patients with coronary heart disease.

METHODS: We conducted a cross-sectional study of 870 patients with stable coronary heart disease. Our primary outcomes were hopelessness score (range 0-8) and hopeless category (low, moderate and high) as measured by the Everson hopelessness scale. Analysis of covariance and ordinal logistic regression were used to examine the independent association of genotype with hopelessness.

RESULTS: Compared to patients with $l / l$ genotype, adjusted odds of a higher hopeless category increased by $35 \%$ for the $l / s$ genotype and $80 \%$ for $s / s$ genotype (p-value for trend=0.004). Analysis of covariance demonstrated that the effect of 5-HTTLPR genotype on hopelessness was modified by sex (.04), but not by racial group $(p=0.63)$. Among men, odds of higher hopeless category increased by $40 \%$ for the $l / s$ genotype and by 2.3 -fold for $s / s$ genotype ( $\mathrm{p}$-value $\mathrm{p}<0.001)$, compared to no effect in the smaller female sample $(\mathrm{p}=$ 0.42). Results stratified by race demonstrated a similar dose-response effect of the $s$ allele on hopelessness across racial groups.

CONCLUSIONS: We found that the 5-HTTLPR is independently associated with hopelessness among men with cardiovascular disease.

KEY WORDS: hopelessness; depression; 5-HTTLPR; cross-sectional; Everson hopelessness scale.

J Gen Intern Med 25(10):1030-7

DOI: $10.1007 / \mathrm{s} 11606-010-1403-0$

(C) The Author(s) 2010. This article is published with open access at Springerlink.com

Findings were presented at the Annual Society of General Internal Medicine meeting on May 14, 2009 in Miami, Florida.

Received October 9, 2009

Revised April 16, 2010

Accepted April 30, 2010

Published online May 28, 2010

\section{BACKGROUND}

Hopelessness, defined as a sense of futility and negative future orientation, is associated with worse medical outcomes ${ }^{1-4}$. Among patients with cardiovascular disease, hopelessness predicts incident myocardial infarction and cardiovascular mortality ${ }^{2}$. Although it is widely accepted that hopelessness is a typical feature of depression ${ }^{5}$, there is substantial evidence for the functional independence of hopelessness and depression ${ }^{6,7}$. Furthermore, hopelessness is more common than depression ${ }^{1,2}$, and the strength of the association between hopelessness and adverse cardiovascular outcomes has been found to be distinct from and stronger than that associated with depression ${ }^{1,8}$.

Several factors impact patients' sense of hope, including socioeconomic status, family support, severity of illness and comorbidities. Genetic predisposition is also likely to play a role, and in recent years, there has been increased interest in investigating the genetic component of both psychiatric disorders and healthy psychiatric characteristics. A breakthrough in this research has been the description of the short (s) allele of 5-HTTLPR (serotonin transporter length polymorphic region), a common functional polymorphism in the promoter region of the serotonin transporter gene (SLC6A4). Compared to the longer (l) allele variant, the $s$ allele results in less efficient transcription of the serotonin transporter gene $\mathrm{e}^{9,10}$, increased cardiac reactivity ${ }^{11}$, and it has been associated with less resilience to the depressogenic effects of adverse life events ${ }^{12}$, poorer response to selective serotonin reuptake inhibitor (SSRI) antidepressant therapy $^{13}$, and with clinical and subclinical depression ${ }^{14-23}$.

Previously, Otte and colleagues found that the short allele of 5-HTTLPR predicted major depressive disorder, higher perceived stress, and norepinephrine secretion in the Heart and Soul Study $^{22}$. However, the association between the 5-HTTLPR polymorphism and depression has more recently been called into question, with a meta-analysis demonstrating no evidence of interaction between the $s$ allele and stressful life events on development of depression ${ }^{24}$. Given the heterogeneity of depression, one possible explanation for these discordant results is that 5-HTTLPR may be associated with some aspects of depression, and not with others. For example, Gonda and colleagues $^{15}$ recently described an association between the $s$ allele of 5-HTTLPR and several elements of "neuroticism-related traits" including anxiety, depression, hopelessness, guilt, hostility, aggression, and somatization in a group of healthy women. Thus, the genetic basis of the components of sub-clinical 
depression may offer insights into this controversy. Further, emerging data has suggested that serotonergic function modulated by 5 -HTTLPR may vary according to age and sex, where patients over 25 years of age and men with $s$ allele carriage have been found to be at increased risk of SSRI non-response compared to younger patients and women ${ }^{25,26}$. Sex differences in 5-HTTLPR moderation of response to SSRI antidepressants, tryptophan depletion and stressful life events have also been observed $^{25,27,28}$.

No study has evaluated whether the 5-HTTLPR $s$ allele is associated with increased susceptibility to hopelessness among patients with chronic illness. We sought to determine whether presence of the $s$ allele is associated with greater propensity to hopelessness in patients with chronic cardiovascular disease independent of depression. The following were our objectives: 1) to determine the independent association between the 5-HTTLPR $s$ allele and hopelessness and 2) to determine whether the effect between 5-HTTLPR $s$ allele and hopelessness was moderated by race, sex, social support or presence of depression.

\section{METHODS}

Sites and subjects. We studied patients enrolled in the Heart and Soul Study, details of which have been published previously ${ }^{29}$. Briefly, participants were prospectively enrolled at 2 Department of Veterans Affairs (VA) medical centers (San Francisco VA Medical Center and VA Palo Alto Health Care System), one university center (University of California, San Francisco) and nine public health clinics in the Community Health Network of San Francisco. Eligible patients had at least one of the following: a history of myocardial infarction, angiographic evidence of $\geq 50 \%$ stenosis in one or more coronary vessels, history of coronary revascularization or prior evidence of exercise-induced ischemia by treadmill or nuclear testing. All study participants completed a self-administered questionnaire during a daylong study appointment. The study was approved by the appropriate institutional review boards and written informed consent was obtained from all participants after complete description of the study.

This analysis includes 870 (85\%) of the 1,024 participants in the Heart and Soul Study. Of the 154 patients excluded, five did not complete the hopelessness survey, one did not provide information on race, 116 patients did not have genotyping, and thirty-two patients had at least one rare 5-HTTLPR variant (generally 18 or 20 repeats), the transcriptional efficiency of which is unknown ${ }^{30}$.

\section{5-HTTLPR Genotyping}

Sample collection, DNA extraction and storage, amplification and genotyping procedures are described elsewhere ${ }^{22}$. Resulting genotypes of 5-HTTLPR were described as $l / l, l / s$ or $s / s$. Laboratory personnel were blind to hopelessness scores.

\section{Hopelessness}

We assessed current hopelessness using the Everson two-item hopelessness scale, a previously validated instrument ${ }^{2}$. The scale contains the following questions: 1) "I feel that it is impossible to reach the goals I would like to strive for", and 2) "The future seems to me to be hopeless, and I can't believe that things are changing for the better". Responses are scored as 0 (absolutely disagree), 1 (somewhat disagree), 2 (cannot say), 3 (somewhat agree), and 4 (absolutely agree), with a summary score ranging from 0 to 8 (higher scores indicate greater hopelessness). We categorized hopelessness as defined by Everson et al. ${ }^{2}$ : Low (0-2), moderate (3-5), high (6-8).

\section{Other Patient Characteristics and Covariates}

Self-reported age, race, gender, marital status, income, education, smoking and alcohol use were determined by selfadministered questionnaire. Race categories included on the survey were 1) Hispanic, Latino, or Latin American; 2) Asian or Pacific Islander; 3) Black or African American; 4) White or Caucasian; 5) Another group not listed. We used the terms: "Latino", "Asian", "African American", "White" and "Other" to describe the groups throughout the manuscript. We measured height and weight and calculated body mass index. Participants were instructed to bring all medication to their appointment where study personnel recorded and categorized medications using Epocrates Rx (San Mateo, California). We measured depressive symptoms using the 9-item Patient Health Questionnaire (PHQ-9) score ${ }^{31,32}$, a self-report instrument that has excellent validity for diagnosing depression in patients with coronary disease ${ }^{33}$, and which also predicts adverse cardiovascular outcomes ${ }^{34}$. We also ascertained the presence of a current major depressive disorder using the Computerized Diagnostic Interview Schedule ${ }^{35}$ for DSM-IV (CDIS-IV). Participants with a major depressive episode in the past month were informed of this diagnosis, instructed to discuss their symptoms with their primary care provider, and provided a list of local resources available for treatment. We measured social support using a single question with a dichotomous response, "Do you have as much contact as you would like with someone you feel close to, someone in whom you can trust and confide?"

\section{Statistical Analysis}

The primary goal of this study was to investigate the independent association between the $s$ allele variant of the 5-HTTLPR polymorphism and hopelessness. We considered autosomal dominant, autosomal recessive and dose-response effects of the $s$ allele in our analysis. Genotypes were classified separately according to levels of transcriptional efficiency ${ }^{9,16}$, where $l / l$ was coded as $0, s / l$ was coded as 1 , and $s / s$ was coded as 2 . In our analysis, the dose response model best characterized the association between 5-HTTLPR genotype and hopelessness.

Differences in characteristics between participants by 5 HTTLPR genotype $(l / l, l / s$ and $s / s)$ were determined using chi square (for dichotomous variables) or analysis of variance (for continuous variables). We used two models to evaluate the association between 5-HTTLPR genotype and measured hopelessness: In the first, we used analysis of covariance to calculate mean hopelessness scores according to genotype. This model was used for its increased sensitivity to test for effect modifying and confounding variables to establish a final adjusted model. We considered the effects of interactions between 5-HTTLPR and potential effect modifiers including race, depressive symptoms, major depressive disorder, antidepressant use, social support, sex and age. Then, we used a proportional odds final adjusted model to estimate the inde- 
pendent association between 5-HTTLPR genotype and hopeless category (low, moderate, high). We verified the proportional odds assumption that the association between 5-HTTLPR genotype and each possible dichotomous outcome variable that could be constructed from the ordinal hopelessness categories (high vs. low-moderate and low vs. moderate-high) can be described by only two odds-ratios, one for $l / s$ and the other for $s / s$.

Covariates. In order to avoid population stratification ${ }^{36-38}$, we adjusted for self-reported race in all pooled and composite "non-white" analyses. In our final adjusted model, we also included as covariates age, antidepressant use and depressive symptoms (PHQ-9 score). These were chosen on the basis of clinical validity and prior literature demonstrating an association between age, depressive symptoms and response to antidepressants with 5-HTTLPR ${ }^{39,40}$. We tested our final model using two sensitivity analyses: 1) We excluded patients with CDIS IV current depressive disorder, and 2) we further adjusted for variables associated $(p<0.10)$ with either 5 HTTLPR or hopelessness score.

Effect Modification. The effect of 5-HTTLPR on hopelessness was modified by sex $(\mathrm{p}=0.04)$. We therefore stratified our analyses according to patient sex, and race, based on an a priori assumption of population stratification by race (though we found no statistical evidence) of interaction between 5-HTTLPR and race, $p=0.63$ ). Racial subgroups were first stratified by "white" and "non-white", in order to evaluate this association in the largest, only adequately powered subgroup (white patients). In a secondary analysis, we present the adjusted association between the $s$ allele and hopeless category in individual minority (non-white) groups. Although underpowered, we intended to evaluate for a trend in the effect of the $s$ allele on hopelessness across racial groups. We also present the results in only the male subgroups as the assumption of proportional odds is violated in females due to small sample size.

To assess for collinearity, we calculated a Spearman correlation coefficient between Everson hopelessness and PHQ9 scores. The analyses were performed using STATA version 10 (STATA Corp, College Station, TX).

\section{RESULTS}

\section{Patient Characteristics}

Within the study cohort ( $\mathrm{n}=870), 282(32 \%)$ were homozygous for the $l$ allele ( $l / l$ genotype), 416 (48\%) were heterozygous $(l / s$ genotype) and $172(20 \%)$ were homozygous for the $s$ allele (s/s genotype). There were no differences in age, sex, antidepressant use, medical illness, education, income, body mass index, alcohol use, social support, and depressive symptoms observed by genotype (Table 1). 5-HTTLPR genotype distribution differed by race (Fig. 1) and was consistent with previous reports in both this cohort ${ }^{22}$ and other patient populations ${ }^{41-43}$, where African American patients had the lowest frequency of $s$ allele carriage. In contrast, Asians had the highest $s$ allele frequency $^{16,17}$. Stratified racial groups were in accordance with Hardy-

Table 1. Characteristics of 870 Participants with Coronary Artery Disease According to 5-HTTLPR Genotype*

\begin{tabular}{|c|c|c|c|c|}
\hline Patient Characteristics & $I / I N=282(32 \%)$ & $I / s \mathrm{~N}=416(48 \%)$ & $s / s \mathrm{~N}=172(20 \%)$ & p-value \\
\hline \multicolumn{5}{|l|}{ Demographic characteristics } \\
\hline Age in Years, mean $\pm \mathrm{SD}$ & $66.7 \pm 11$ & $66.9 \pm 11$ & $66.5 \pm 11$ & 0.89 \\
\hline Male & $225(80)$ & $340(82)$ & $145(84)$ & 0.48 \\
\hline Self-Reported Race/Ethnicity & & & & $<0.001$ \\
\hline White & $170(60)$ & $285(69)$ & $92(53)$ & \\
\hline African American & $79(28)$ & $37(9)$ & $12(7)$ & \\
\hline Asian & $10(4)$ & $39(9)$ & $37(22)$ & \\
\hline Latino & $17(6)$ & $41(10)$ & $22(13)$ & \\
\hline Other & $6(2)$ & $14(3)$ & $9(5)$ & \\
\hline Married & $119(42)$ & $175(42)$ & $73(42)$ & 0.99 \\
\hline High School Graduate & $244(87)$ & $366(88)$ & $148(86)$ & 0.76 \\
\hline Median Income Category in $\$ \dagger$ & $20-29,999$ & $20-29,999$ & $10-19,999$ & 0.54 \\
\hline \multicolumn{5}{|l|}{ Medical History } \\
\hline Hypertension & $209(74)$ & $286(69)$ & $117(68)$ & 0.21 \\
\hline Myocardial infarction & $146(52)$ & $235(57)$ & $87(51)$ & 0.32 \\
\hline Stroke & $34(12)$ & $60(14)$ & $29(17)$ & 0.35 \\
\hline Diabetes Mellitus§ & $68(24)$ & $106(25)$ & $53(31)$ & 0.27 \\
\hline \multicolumn{5}{|l|}{ Medication Use } \\
\hline Antidepressant & 53 (19) & $84(20)$ & $30(17)$ & 0.73 \\
\hline Benzodiazepine or anxiolytic & $34(12)$ & $53(13)$ & $13(8)$ & 0.19 \\
\hline Angiotensin receptor blocker & $151(54)$ & $209(50)$ & $93(54)$ & 0.58 \\
\hline Beta-blocker & $151(54)$ & 246 (59) & $98(57)$ & 0.34 \\
\hline \multicolumn{5}{|l|}{ Other Characteristics } \\
\hline Body mass index, mean $\pm \mathrm{SD}$ & $28.7 \pm 6$ & $28.1 \pm 5$ & $28.6 \pm 5$ & 0.37 \\
\hline Regular alcohol use & $85(30)$ & $119(29)$ & $47(27)$ & 0.80 \\
\hline Current smoking & $68(24)$ & $75(18)$ & $30(17)$ & 0.10 \\
\hline Presence of social support & $194(69)$ & $269(65)$ & $115(67)$ & 0.51 \\
\hline \multicolumn{5}{|l|}{ Measures of Depression } \\
\hline Depressive Symptoms (PHQ-9 score), mean \pm SD & $5.2 \pm 5.3$ & $5.2 \pm 5.4$ & $5.1 \pm 5.7$ & 0.97 \\
\hline Current Depression by CDIS-IV & $55(20)$ & $102(25 \%)$ & $35(20)$ & 0.24 \\
\hline
\end{tabular}

*All numbers given as $N$ (\%) except where otherwise indicated; $\dagger$ Out of a total of 865 patients (5 patients missing income data)

$\S$ Out of a total of 869 patients (1 patient missing history of diabetes) 


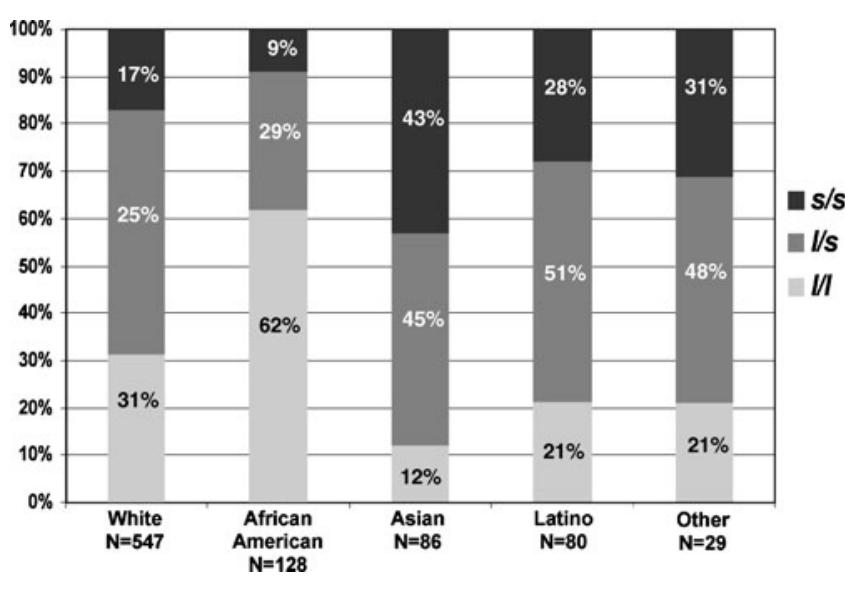

Figure 1. Genotype frequency by self-reported race among 870 participants with coronary artery disease.

Weinberg equilibrium ( $>0.10$ ), except in the African American sample $(\mathrm{p}=0.02)$, where homozygotes (both $l / l$ and $s / s$ ) were over-represented.

The 154 excluded patients were more likely to be Asian (21\% versus $10 \%$ ) or African American (26\% versus 15\%), largely due to increased frequency of rare 5-HTTLPR variants (15 Asians, 16 African Americans and 1 White patient), and less likely to be White (44\% versus $63 \%$ ) or Latino (6\% versus $9 \%$ ), but they did not differ according to other demographic or clinical characteristics listed in Table 1 (data not shown).

\section{5-HTTLP and Hopelessness}

Hopelessness was common in this sample, with $52 \%$ of patients scoring as either moderate $(\mathrm{N}=333,38 \%)$ or high $(\mathrm{N}=$ $119,14 \%$ ) hopelessness. The overall distribution of hopelessness scores by genotype (Fig. 2) shows a proportionate increase of $s$ allele carriage in higher hopelessness categories ( $p$ value trend $=0.006$ ) in the pooled sample. Hopeless category did not vary according to sex, age or race ( $p>0.40)$. After adjustment for self-reported race, mean hopelessness scores increased linearly with the addition of each $s$ allele $(0.015$, no evidence of departure from trend, $\mathrm{p}=0.96$ ), ranging from $2.5 \pm 0.1$ among patients with the $l / l$ genotype to $3.1 \pm 0.1$ among patients with the $s / s$ genotype (Table 2). Results were strengthened after further adjustment for age, antidepressant use, and depressive symptoms ( $\mathrm{PHQ}-9$ score) $(\mathrm{p}=0.004)$. Results were unchanged ( $\mathrm{p}$ $=0.002$ ) after further adjustment for income, marital status, high school graduation, smoking, social support and hypertension (association between these covariates and genotype or hopelessness $\mathrm{p}<0.10$ ). Although we found significant Spearman correlation between PHQ-9 and Everson Hopelessness scores $(\mathrm{p}<0.001)$, the coefficient of 0.38 was not concerning for collinearity.

\section{Effect Modification by Sex}

We did not find differences in the effect of 5-HTTLPR genotype on hopelessness by age ( $\mathrm{p}$-value for interaction $=0.29)$, race $(\mathrm{p}=$ $0.63)$ antidepressant use $(p=0.35)$, marital status $(p=0.94)$, social support $(\mathrm{p}=0.17)$, depressive symptoms $(\mathrm{p}=0.18)$ or CDIS IV current depression $(\mathrm{p}=0.88)$. Adjusted results strati- fied by sex ( $p$ value for interaction=0.04) demonstrated an association between the 5-HTTLPR genotype and mean hopelessness score in males $(p=0.001)$ but not in females $(p=0.76)$ (Table 2).

\section{Findings in Non-Depressed Patients}

Although we found no statistical evidence of interaction between 5-HTTLPR genotype and current depression (p-value= 0.88), we excluded 192 patients with current major depressive disorder as defined by CDIS-IV to evaluate the association between 5-HTTLPR genotype and hopelessness in non-depressed patients. In the 678 nondepressed patients, we found a similar trend of increasing mean hopelessness scores with each added $s$ allele ( $\mathrm{p}=0.007$ in the adjusted model) (Table 2). After stratification by sex, we observed this effect only in the male sub-group.

\section{5-HTTLPR and Hopeless Category}

Using ordinal regression, we found that compared to patients with $l / l$ genotype in the pooled sample, adjusted (using covariates of race, age, antidepressant use and depressive symptoms) odds of higher hopeless category increased by $35 \%$ for $s / l$ genotype and $80 \%$ for $s / s$ genotype (p-value for trend= 0.004) (Fig. 3). On analysis stratified by sex, we found that this association was driven by its strong association only in the larger male subgroup (Male: $l / s$ OR 1.41, 95\% CI 0.99-2.0; s/s OR 2.23, 95\% CI 1.5-3.4, p<0.001; Female: $l / s$ OR 1.17, 95\% CI $0.57-2.4, \mathrm{~s} / \mathrm{s}$ OR $0.66,95 \%$ CI $0.24-1.8, \mathrm{p}=0.42$ ), where males with $\mathrm{s} / \mathrm{s}$ genotype were at 2.2 -fold increased odds of higher hopeless category compared to $l / l$ males. After stratification by "White" and "Non-white" racial groups, we found statistically significant odds of higher hopeless category with each increasing $s$ allele in each of the male subgroups (White male: $l / s$ OR $1.24,95 \%$ CI $0.81-1.9$, s/s OR 2.32, 95\% CI $1.3-$ 4.0, $\mathrm{p}=0.003$; Non-white male: $l / s$ OR 1.72 , 95\% CI 0.95-3.12, $s / s$ OR $2.18,95 \%$ CI 1.1-4.2, $\mathrm{p}=0.02$ ), but no effect in females ( $>0.40$ ) (Fig. 3). There was no statistical evidence for interac-

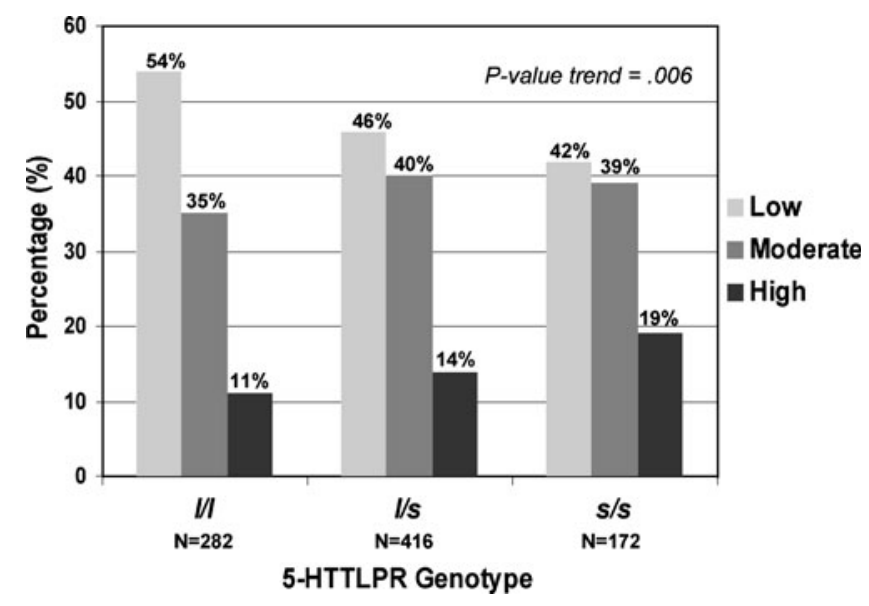

Figure 2. Hopeless category by genotype, where low $=$ score $\leq 2$, moderate $=$ score $3-5$, and high $=$ score $\geq 6$ on the Everson hopelessness scale. The percentage of patients with low hopelessness decreases with increased $s$ allele carriage, whereas the percentage of patients with high hopelessness increases with $s$ allele carriage, $p$ value for trend $=0.006$. 
Table 2. Mean Hopelessness Score by 5-HTTLPR Genotype

\begin{tabular}{|c|c|c|c|c|}
\hline Model & $I / I$ & $I / s$ & $s / s$ & p-value (trend) \\
\hline All study participants $(n=870)$ & $282(32 \%)$ & $416(48 \%)$ & $171(20 \%)$ & \\
\hline Adjusted by race & $2.5 \pm 0.1$ & $2.8 \pm 0.1$ & $3.1 \pm 0.2$ & 0.015 \\
\hline Adjusted by race, age, depressive symptoms and antidepressant use & $2.5 \pm 0.1$ & $2.8 \pm 0.1$ & $3.1 \pm 0.1$ & 0.004 \\
\hline Males $(n=710)$ & $2.5 \pm 0.1$ & $2.9 \pm 0.1$ & $3.3 \pm 0.2$ & 0.001 \\
\hline Females $(n=160)$ & $2.4 \pm 0.3$ & $2.6 \pm 0.2$ & $2.2 \pm 0.4$ & 0.76 \\
\hline Non-depressed participants $(n=678)$ & $227(33 \%)$ & $314(46 \%)$ & $137(20 \%)$ & \\
\hline Adjusted by race & $2.4 \pm 0.2$ & $2.6 \pm 0.2$ & $3.0 \pm 0.2$ & 0.03 \\
\hline Adjusted by race, age, depressive symptoms, and antidepressant use & $2.3 \pm 0.2$ & $2.5 \pm 0.2$ & $2.9 \pm 0.2$ & 0.007 \\
\hline Males $(n=579)$ & $2.3 \pm 0.2$ & $2.6 \pm 0.2$ & $3.0 \pm 0.2$ & 0.004 \\
\hline Females $(n=99)$ & $2.1 \pm 0.5$ & $2.2 \pm 0.4$ & $2.7 \pm 0.5$ & 0.48 \\
\hline
\end{tabular}

tion between 5-HTTLPR and race (p-value for interaction term =0.84). We stratified by individual minority groups (Fig. 4), which demonstrated a similar trend of increased odds of higher hopeless category associated with $s$ allele carriage across male racial subgroups in this sample.

\section{DISCUSSION}

In this cross-sectional study of 870 patients with stable coronary artery disease, we found that the $s$ allele of the 5HTT polymorphic region predicted higher propensity to hopelessness that persisted after controlling for age, depressive symptoms, major depressive disorder, and antidepressant use. Further, this association was present only in male patients, where males with the $s / s$ genotype had more than 2 -fold increased odds of a higher hopeless category than $l / l$ males across racial subgroups. We did not find any association between 5-HTTLPR genotype and hopelessness in the female sample in this study. Additionally, we did not find that the effect between 5-HTTLPR genotype and hopelessness was modified by race, depression (CDIS IV), depressive symptoms (PHQ-9), antidepressant use, social support or age. After excluding the 192 depressed patients, we saw a similar association between 5-HTTLPR genotype and hopelessness. Our findings suggest that hopelessness may be partly heritable and that the serotonin (5-HT) system is likely to be involved. Further, these results suggest that the $s$ allele may increase susceptibility to hopelessness in men with chronic cardiovascular disease independent of depressive symptoms or major depressive disorder.

Hopelessness is common in cardiovascular patients and leads to increased cardiovascular morbidity and mortality ${ }^{1}$. This study demonstrates that there is a dose response relationship between 5-HTTLPR s allele carriage and higher hopelessness in men with chronic cardiovascular disease. Across racial groups, the odds were more than doubled for a higher hopeless category in men with the $s / s$ genotype compared to $l / l$ genotype. The 2 -item Everson Hopelessness scale has been validated in cardiovascular patients, and moderate and high hopelessness has been linked in a dose response fashion with all-cause and cardiovascular-specific mortality independent of depression ${ }^{2}$. The findings of this study illuminate underlying mechanisms for this important and under-recognized phenotype.

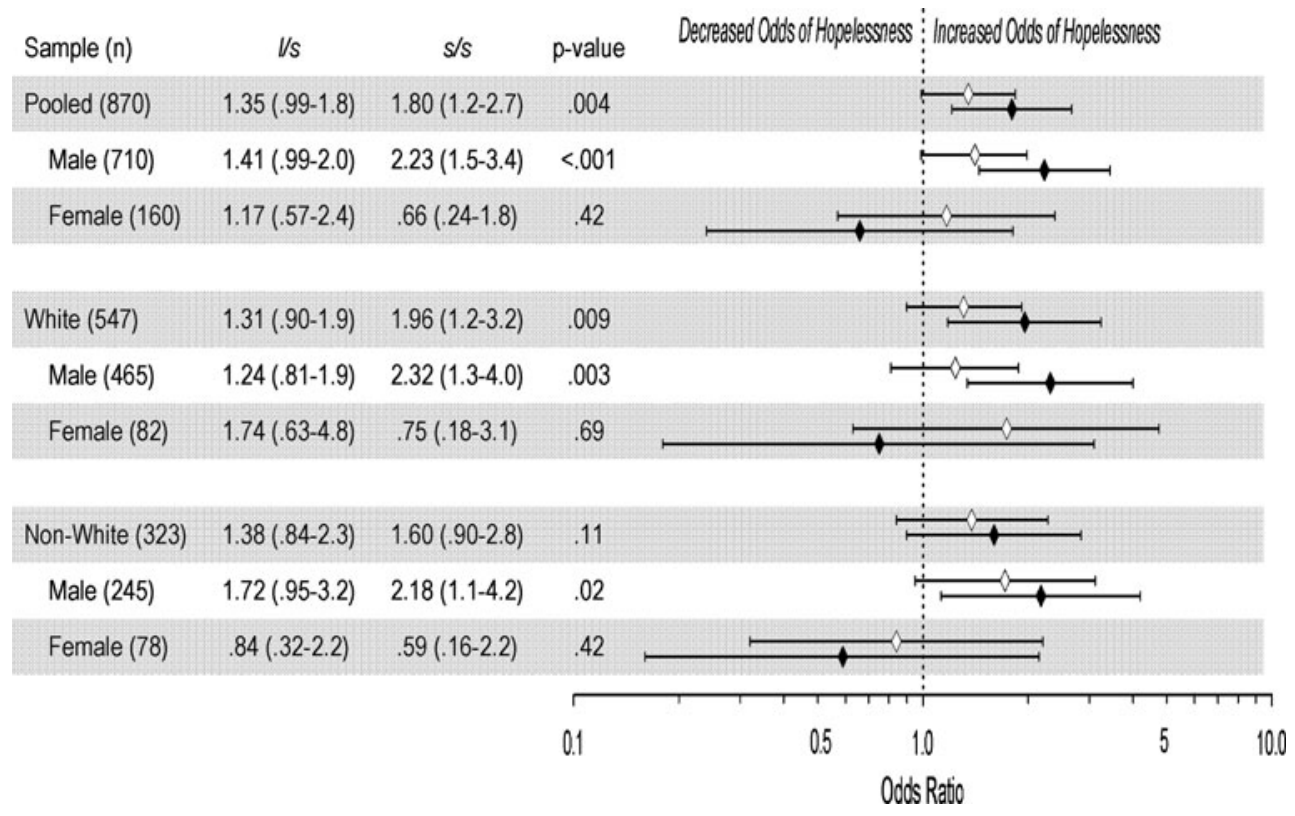

Figure 3. Adjusted odds of higher hopeless category (low/moderate/high) in $I / s$ (white diamonds) and $s / s$ (black diamonds) genotype compared to $\mathrm{I} / \mathrm{I}$ referent among 870 patients with coronary disease. 


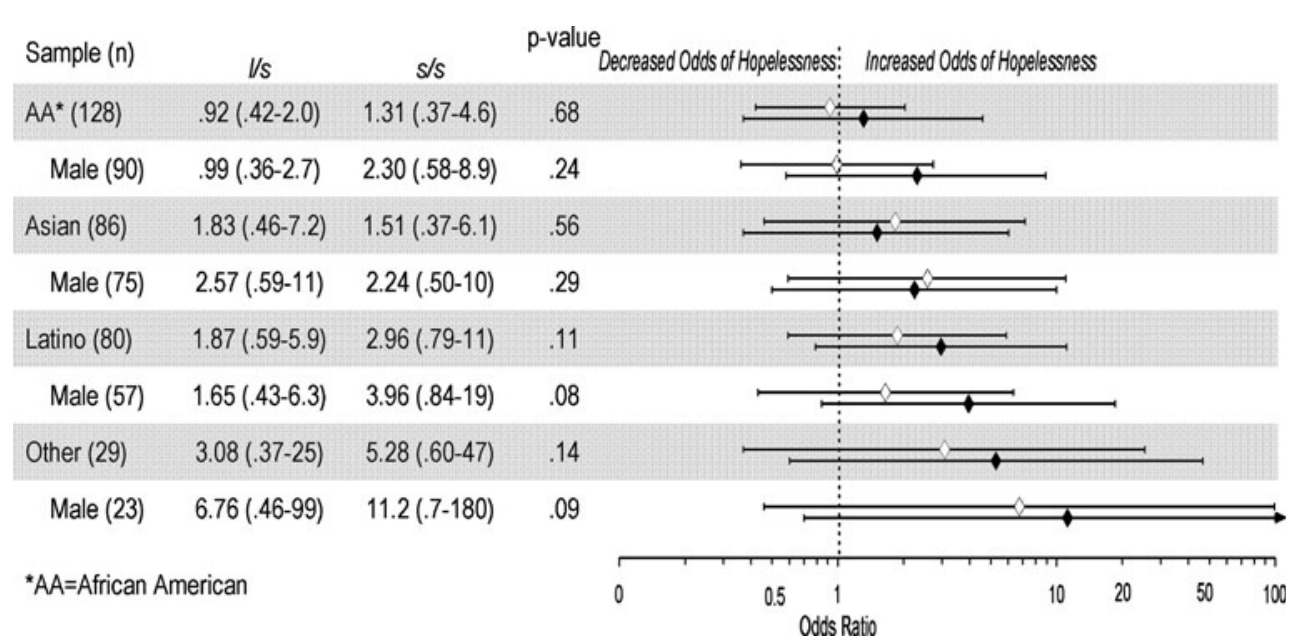

Figure 4. Adjusted odds of higher hopeless category (low/moderate/high) in $I / s$ (white diamonds) and $s / s$ (black diamonds) genotype compared to $\mathrm{I} / \mathrm{I}$ referent according to self-reported race among 323 minority (non-white) patients with coronary disease.

\section{Sex and Age Effects}

The marked effect of 5-HTTLPR on measured hopelessness in men but not in women is consistent with prior reports of sexspecific genetic influences on serotonergic function ${ }^{44}$. It has been demonstrated that ovarian steroids stimulate expression of the serotonin transporter ${ }^{45,46}$, and the impact of a less functional $s$ allele may be moderated by an estrogen-induced protective effect in women. Increased age has been associated with decreased serotonergic function; however, the protective effect of age related to 5-HTTLPR moderation antidepressant response has only been found in patients under 25 years of age $^{26}$. As our sample was older, it was not surprising that there was no evidence of interaction between 5-HTTLPR and age.

\section{Race Effects}

Although we found no statistical evidence of interaction by race, we accounted for the possibility that the allele frequency differences between racial groups modified the relationship between 5-HTTLPR and hopelessness by stratifying our analysis by race and adjusting for race in pooled analyses. This addresses the concern of bias by population stratification, where 5-HTTLPR variation between racial groups may be a marker of different genetic and environmental factors leading to hopelessness in each of these groups rather than the etiology itself $^{41}$. Across races, we found a similar linear association between 5-HTTLPR and hopelessness.

\section{Genetics of Hopelessness}

There has been very little research on the genetics of hopelessness. The only prior study by Gonda and colleagues ${ }^{15}$ first identified the association between the 5-HTTLPR $s$ allele and hopelessness as part of an evaluation of neuroticism traits in healthy, young, white women. In comparison, we found an association in older men with significant cardiovascular disease, but no effect in the minority of women in the study. Additionally, whereas our study used the Everson scale to measure hopelessness, Gonda et al. used the Beck hopelessness scale ${ }^{47}$. Although correlation between these scoring systems has not been evaluated, items on the scales are similar.

The constructs of hopelessness and depression are difficult to disentangle as hopelessness is often a fundamental characteristic of depression. However, it has been proposed that hopelessness may be a distinct phenotype from depression and the independent association between the 5-HTTLPR genotype and measured hopelessness in this sample supports this hypothesis. Scales measuring hopelessness and depression differ: whereas depression scales focus on mood alteration, hopelessness scales measure future orientation ${ }^{6}$. Our results suggest that pathophysiological differences may exist between these two constructs as well. Is hopelessness really just a marker of "sub-threshold" depression, one that is poorly measured by traditional depression scales? Or is it a separate entity often present in depression, but a functionally independent construct? The independent association with 5-HTTLPR $s$ allele suggests that measured constructs of hopelessness and depression are independent entities. Our results may also provide new insights on the heterogeneity of results in the evaluation of 5-HTTLPR and depression.

\section{Strengths and Limitations}

Our study is the largest to date to evaluate the association between 5-HTTLPR polymorphism and hopelessness. However, it is only powered to detect associations in the largest subgroups (white race, male sex). Women were underrepresented, and our current negative results do not rule out the possibility of a type II error. Similarly, the association between 5-HTTLPR and hopelessness in males is a novel finding that will have to be tested in other large samples. Further, results in the Latino and African American groups are further limited by possible population stratification, due to the racial admixture present in these groups. However, the results in the non-white groups serve to identify trends as the basis for more robust future studies and meta-analyses. Lastly, it is not known whether increased hopelessness associated with 5-HTTLPR $s$ allele is associated with meaningful clinical outcomes, such as increased cardiovascular mortality or SSRI resistance. 
Although our interaction term between 5-HTTLPR and antidepressant use was not statistically significant, only $19 \%$ of patients in our cohort were on any type of antidepressant, with only half that number on SSRIs; therefore, our power to detect the interaction in this cohort was small. Prior work by Otte et al. $^{22}$ demonstrated an association between the 5-HTTLPR $s$ allele and increased norepinephrine secretion in Heart and Soul. This finding along with other reports that the $s$ allele moderates cardiac reactivity ${ }^{11}$ and increased cardiac events mediated by depressive symptoms, ${ }^{48}$ suggest that 5 -HTTLPR may play a larger role in cardiovascular health outcomes. Lastly, although our sample included only highly educated adults with cardiovascular disease, we suspect that the association between 5-HTTLPR and hopelessness may be similar in other populations. Despite these limitations we find an independent association between the 5-HTTLPR $s$ allele and significantly increased hopelessness in men with cardiovascular disease.

In conclusion, we found that the 5-HTTLPR $s$ allele was associated with increased susceptibility to hopelessness in men with cardiovascular disease, independent of depressive symptoms and major depressive disorder.

Acknowledgments: Thank you to Dr. John Witte for his assistance in addressing issues related to population stratification. The Heart and Soul Study was supported by grants from the Department of Veterans Affairs (VA) Epidemiology Merit Review Program, the VA Health Services Research and Development Service, the Robert Wood Johnson Foundation (Generalist Physician Faculty Scholars Program), the American Federation for Aging Research (Paul Beeson Faculty Scholars in Aging Research Program), and the Ischemia Research and Education Foundation. Dr. Kangelaris was supported by a National Research Service Award (NRSA) institutional grant (T32 HP19025). None of these funding sources had any role in the collection of data, interpretation of results, or preparation of this manuscript.

\section{Conflict of Interest: None disclosed.}

Open Access: This article is distributed under the terms of the Creative Commons Attribution Noncommercial License which permits any noncommercial use, distribution, and reproduction in any medium, provided the original author(s) and source are credited.

Corresponding Author: Kirsten Neudoerffer Kangelaris, MD; Parnassus Ave UC Hall, University of California, San Francisco, Box 0131, 533, San Francisco, CA 94143-0131, USA (e-mail: kkangelaris@medicine.ucsf.edu).

\section{REFERENCES}

1. Anda R, Williamson D, Jones D, et al. Depressed affect, hopelessness, and the risk of ischemic heart disease in a cohort of U.S. adults. Epidemiology. 1993;4(4):285-94.

2. Everson SA, Goldberg DE, Kaplan GA, et al. Hopelessness and risk of mortality and incidence of myocardial infarction and cancer. Psychosom Med. 1996;58(2):113-21.

3. Everson SA, Kaplan GA, Goldberg DE, Salonen JT. Hypertension incidence is predicted by high levels of hopelessness in Finnish men. Hypertension. 2000;35(2):561-7.

4. Everson SA, Kaplan GA, Goldberg DE, Salonen R, Salonen JT. Hopelessness and 4-year progression of carotid atherosclerosis. 1495. Arterioscler Thromb Vasc Biol. 1997;17(8):1490-5.

5. Melges FT, Bowlby J. Types of hopelessness in psychopathological process. Arch Gen Psychiatry. 1969;20(6):690-9.
6. Greene SM. The relationship between depression and hopelessness. Implications for current theories of depression. Br J Psychiatry. 1989; 154:650-9.

7. Nekanda-Trepka CJ, Bishop S, Blackburn IM. Hopelessness and depression. Br J Clin Psychol. 1983;22(Pt 1):49-60.

8. Whipple MO, Lewis TT, Sutton-Tyrrell K, et al. Hopelessness, depressive symptoms, and carotid atherosclerosis in women: the Study of Women's Health Across the Nation (SWAN) heart study. Stroke. 2009;40 (10):3166-72.

9. Heils A, Teufel A, Petri S, et al. Allelic variation of human serotonin transporter gene expression. J Neurochem. 1996;66(6):2621-4.

10. Greenberg BD, Tolliver TJ, Huang SJ, Li Q, Bengel D, Murphy DL. Genetic variation in the serotonin transporter promoter region affects serotonin uptake in human blood platelets. Am J Med Genet. 1999;88 (1):83-7.

11. McCaffery JM, Bleil M, Pogue-Geile MF, Ferrell RE, Manuck SB. Allelic variation in the serotonin transporter gene-linked polymorphic region (5-HTTLPR) and cardiovascular reactivity in young adult male and female twins of European-American descent. Psychosom Med. 2003;65 (5):721-8.

12. Uher $\mathbf{R}$, McGuffin $\mathbf{P}$. The moderation by the serotonin transporter gene of environmental adversity in the aetiology of mental illness: review and methodological analysis. Mol Psychiatry. 2008;13(2):13146.

13. Smeraldi E, Zanardi R, Benedetti F, Di Bella D, Perez J, Catalano M. Polymorphism within the promoter of the serotonin transporter gene and antidepressant efficacy of fluvoxamine. Mol Psychiatry. 1998;3(6):50811.

14. Gonda X, Juhasz G, Laszik A, Rihmer Z, Bagdy G. Subthreshold depression is linked to the functional polymorphism of the $5 \mathrm{HT}$ transporter gene. J Affect Disord. 2005;87(2-3):291-7.

15. Gonda X, Fountoulakis KN, Juhasz G, et al. Association of the s allele of the 5-HTTLPR with neuroticism-related traits and temperaments in a psychiatrically healthy population. Eur Arch Psychiatry Clin Neurosci. 2009;259(2): 106-13.

16. Lesch KP, Bengel D, Heils A, et al. Association of anxiety-related traits with a polymorphism in the serotonin transporter gene regulatory region. Science. 1996;274(5292):1527-31.

17. Caspi A, Sugden $\mathbf{K}$, Moffitt TE, et al. Influence of life stress on depression: moderation by a polymorphism in the 5-HTT gene. Science. 2003;301(5631):386-9.

18. Eley TC, Sugden K, Corsico A, et al. Gene-environment interaction analysis of serotonin system markers with adolescent depression. Mol Psychiatry. 2004;9(10):908-15.

19. Hoefgen B, Schulze TG, Ohlraun S, et al. The power of sample size and homogenous sampling: association between the 5-HTTLPR serotonin transporter polymorphism and major depressive disorder. Biol Psychiatry. 2005;57(3):247-51

20. Jacobs N, Kenis G, Peeters F, Derom C, Vlietinck R, van Os J. Stressrelated negative affectivity and genetically altered serotonin transporter function: evidence of synergism in shaping risk of depression. Arch Gen Psychiatry. 2006;63(9):989-96.

21. Kendler KS, Kuhn JW, Vittum J, Prescott CA, Riley B. The interaction of stressful life events and a serotonin transporter polymorphism in the prediction of episodes of major depression: a replication. Arch Gen Psychiatry. 2005;62(5):529-35.

22. Otte C, McCaffery J, Ali S, Whooley MA. Association of a serotonin transporter polymorphism (5-HTTLPR) with depression, perceived stress, and norepinephrine in patients with coronary disease: the Heart and Soul Study. Am J Psychiatry. 2007;164(9):1379-84

23. Wilhelm K, Mitchell PB, Niven $\mathbf{H}$, et al. Life events, first depression onset and the serotonin transporter gene. Br J Psychiatry. 2006;188: 210-5.

24. Risch N, Herrell R, Lehner T, et al. Interaction between the serotonin transporter gene (5-HTTLPR), stressful life events, and risk of depression: a meta-analysis. JAMA. 2009;301(23):2462-71.

25. Huezo-Diaz P, Uher R, Smith R, et al. Moderation of antidepressant response by the serotonin transporter gene. Br J Psychiatry. 2009;195 (1):30-8.

26. Joyce PR, Mulder RT, Luty SE, et al. Age-dependent antidepressant pharmacogenomics: polymorphisms of the serotonin transporter and G protein beta3 subunit as predictors of response to fluoxetine and nortriptyline. Int J Neuropsychopharmacol. 2003;6(4):339-46.

27. Sjoberg RL, Nilsson KW, Nordquist $\mathbf{N}$, et al. Development of depression: sex and the interaction between environment and a promoter 
polymorphism of the serotonin transporter gene. Int $\mathrm{J}$ Neuropsychopharmacol. 2006;9(4):443-9.

28. Walderhaug E, Magnusson A, Neumeister A, et al. Interactive effects of sex and 5-HTTLPR on mood and impulsivity during tryptophan depletion in healthy people. Biol Psychiatry. 2007;62(6):593-9.

29. Ruo B, Rumsfeld JS, Hlatky MA, Liu H, Browner WS, Whooley MA Depressive symptoms and health-related quality of life: the Heart and Soul Study. JAMA. 2003;290(2):215-21.

30. Xie P, Kranzler HR, Poling J, et al. Interactive effect of stressful life events and the serotonin transporter 5-HTTLPR genotype on posttraumatic stress disorder diagnosis in 2 independent populations. Arch Gen Psychiatry. 2009;66(11):1201-9.

31. Kroenke K, Spitzer RL, williams JB. The PHQ-9: validity of a brief depression severity measure. J Gen Intern Med. 2001;16(9):606-13.

32. Spitzer RL, Kroenke K, Williams JB. Validation and utility of a selfreport version of PRIME-MD: the PHQ primary care study. Primary care evaluation of mental disorders. Patient health questionnaire. JAMA. 1999;282(18): 1737-44.

33. McManus D, Pipkin SS, Whooley MA. Screening for depression in patients with coronary heart disease (data from the Heart and Soul Study). Am J Cardiol. 2005;96(8):1076-81.

34. Whooley MA, de Jonge P, Vittinghoff E, et al. Depressive symptoms, health behaviors, and risk of cardiovascular events in patients with coronary heart disease. JAMA. 2008;300(20):2379-88.

35. Robins LN, Helzer JE, Croughan J, Ratcliff KS. National Institute of mental health diagnostic interview Schedule. Its history, characteristics, and validity. Arch Gen Psychiatry. 1981;38(4):381-9.

36. Wacholder S, Rothman N, Caporaso N. Population stratification in epidemiologic studies of common genetic variants and cancer: quantification of bias. J Natl Cancer Inst. 2000;92(14):1151-8.

37. Hattersley AT, McCarthy MI. What makes a good genetic association study? Lancet. 2005;366(9493):1315-23.

38. Schulze TG, McMahon FJ. Genetic association mapping at the crossroads: which test and why? Overview and practical guidelines. Am J Med Genet. 2002;114(1):1-11.
39. Gillespie NA, Whitfield JB, Williams B, Heath AC, Martin NG. The relationship between stressful life events, the serotonin transporter (5-HTTLPR) genotype and major depression. Psychol Med. 2005;35 (1):101-11.

40. Grabe HJ, Lange M, Wolff $\mathbf{B}$, et al. Mental and physical distress is modulated by a polymorphism in the 5-HT transporter gene interacting with social stressors and chronic disease burden. Mol Psychiatry. 2005; 10(2):220-4.

41. Gelernter J, Kranzler H, Cubells JF. Serotonin transporter protein (SLC6A4) allele and haplotype frequencies and linkage disequilibria in African- and European-American and Japanese populations and in alcohol-dependent subjects. Hum Genet. 1997;101(2):243-6.

42. Konishi T, Smith JL, Lin KM, Wan YJ. Influence of genetic admixture on polymorphisms of alcohol-metabolizing enzymes: analyses of mutations on the CYP2E1, ADH2, ADH3 and ALDH2 genes in a MexicanAmerican population living in the Los Angeles area. Alcohol Alcohol. 2003;38(1):93-4.

43. Nakamura T, Muramatsu T, Ono Y, et al. Serotonin transporter gene regulatory region polymorphism and anxiety-related traits in the Japanese. Am J Med Genet. 1997;74(5):544-5.

44. Weiss LA, Abney M, Cook EH Jr, Ober C. Sex-specific genetic architecture of whole blood serotonin levels. Am J Hum Genet. 2005;76 (1):33-41.

45. Lu NZ, Eshleman AJ, Janowsky A, Bethea CL. Ovarian steroid regulation of serotonin reuptake transporter (SERT) binding, distribution, and function in female macaques. Mol Psychiatry. 2003;8(3):353-60.

46. McQueen JK, Wilson H, Fink G. Estradiol-17 beta increases serotonin transporter (SERT) mRNA levels and the density of SERT-binding sites in female rat brain. Brain Res Mol Brain Res. 1997;45(1):13-23.

47. Beck AT, Weissman A, Lester D, Trexler L. The measurement of pessimism: the hopelessness scale. J Consult Clin Psychol. 1974;42 (6):861-5.

48. Nakatani D, Sato $\mathbf{H}$, Sakata $\mathbf{Y}$, et al. Influence of serotonin transporter gene polymorphism on depressive symptoms and new cardiac events after acute myocardial infarction. Am Heart J. 2005;150(4):652-8. 